\section{Responsabilidad Social y Ambiental: Tratamiento y Disposición Final de Llantas Usadas en la Ciudad de Machala}

\author{
Social and Environmental Responsibility: Treatment and \\ Final Disposal of Used Tires in The City of Machala
}

\begin{abstract}
RESUMEN
El presente trabajo bibliográfico y documental se basa en analizar alternativas como por ejemplo: un modelo de gestión de responsabilidad social y ambiental para el tratamiento de los neumáticos usados en la ciudad de Machala, provincia El Oro, Ecuador; para lo cual se obtuvieron datos estadísticos procedentes de organismos públicos y páginas oficiales. Además, se efectuaron visitas a sitios en donde se están implementando alternativas para disminuir la problemática de los neumáticos en desuso cuando terminan su vida útil y de esta manera aprovecharla como materia prima. Esto ha permitido conocer la problemática presente en la ciudad, mediante la relación entre las variables: crecimiento poblacional y el número de automóviles matriculados anualmente en esta ciudad y la afectación de este residuo especial al medio natural y a la salud humana. Se diseña un modelo de responsabilidad social y ambiental basado en la norma ISO 26000 a través del establecimiento de pauta de conducta para las empresas que se encarguen de darle un valor agregado a los neumáticos usados. Se concluye que el uso de alternativas eficientes para la generación de un valor agregado a partir de los neumáticos usados se considera como un modelo de responsabilidad social y ambiental que ayudará a disminuir la problemática ocasionada por los neumáticos usados luego de su vida útil.
\end{abstract}

Palabras claves: Responsabilidad social y ambiental; neumáticos usados; población; parque automotor y valor agregado.

\begin{abstract}
The present bibliographic and documentary work is based on analyzing alternatives such as: a management model of social and environmental responsibility for the treatment of used tires in the city of Machala, El Oro province, Ecuador, for which data were obtained statistics from public bodies and official pages. In addition, visits were made to sites where alternatives are being implemented to reduce the problem of disused tires when they end their useful life and thus take advantage of them as raw material. This has allowed to know the problems present in the city, through the relationship between the variables: population growth and the number of cars registered annually in this city and the impact of this special
\end{abstract}

Leonardo Espinoza Enríquez $^{1}$

lespinoza2@utmachala.edu.ec

Jonathan Fariño Jimenez ${ }^{1}$

jfarino1@utmachala.edu.ec

Yuri Patricio Espinoza ${ }^{2}$

yuri.patricio.espinoza@upc.edu.es

Miguel Mayorga Cárdenas ${ }^{2}$

miguel.mayorga@upc.edu.es

${ }^{1}$ Universidad Técnica de Machala, Ecuador

${ }^{2}$ Universidad Politécnica de Cataluña, España 
waste on the natural environment and human health. A social and environmental responsibility model is designed based on the ISO 26000 standard through the establishment of a guideline for companies that are in charge of giving added value to used tires. It is concluded that the use of efficient alternatives to generate an added value from used tires is considered as a model of social and environmental responsibility that will help reduce the problems caused by used tires after their useful life.

Keywords: Social and environmental responsibility; used tires; population; car park and added value.

\section{INTRODUCCIÓN}

A nivel mundial existe un aumento considerable del parque automotor, especialmente en los países desarrollados donde hay un crecimiento económico acelerado, así lo da a conocer la Asociación Europea de Neumáticos Reciclados (ETRMA, 2011). Estiman que en el año 2010 existían cerca de 1.41 mil millones de vehículos circulando, que equivale a 0.3 vehículos por individuo.

Más de dos tercios (71,2 \%) son automóviles, el $25,6 \%$ son motocicletas y el $3,1 \%$ son vehículos medianos y pesados. Estas cifras han ido aumentando en un 78\% entre los años 2000 y 2015 . Un $36 \%$ de los vehículos se encuentran en Asia, de los cuales un $13 \%$ en China.

Saquinga (2017) cita los reportes estadísticos de la IndustriALL Global Union y manifiesta que debido a este incremento desmesurado de la producción mundial de vehículos, la generación de neumáticos en el año 2013 fue de mil millones de neumáticos, los mismos que cuando terminan su vida útil, vienen a ser 17 millones de Neumáticos Fuera de Uso (NFU).

Según el Instituto Nacional Ecuatoriano de Censos (INEC, 2014) a nivel nacional se encontraban registrados 1'752.712 vehículos, de este número, si se toma en cuenta un promedio de 4 neumáticos por vehículo se puede calcular que se produjeron unos 7'108.480 NFU si se descuenta el pequeño porcentaje utilizado para los servicios de reencauche, más de cinco millones de unidades quedarían en teoría sin un manejo eficiente. (Saquinga, 2017)

En la ciudad de Machala, al relleno sanitario llegan cerca de 333, 11 toneladas diarias de desechos, entre ellos pilas, baterías, fluorescente y NFU (El Correo, 2019). Esto provoca que el relleno sanitario en poco tiempo llegue a su máxima capacidad de retención, acortando su tiempo de vida útil. De igual manera se puede indicar que no existen empresas que se dediquen al tratamiento eficiente de estos desechos que según el Acuerdo Ministerial 142 son considerados como desechos especiales.

El Ministerio del Ambiente del Ecuador (2013) como Autoridad Ambiental Nacional, ha establecido normas para poder gestionar a los NFU, para ello se expidió un Plan para Neumáticos Usados, cuyos principios están basados en la Responsabilidad Extendida de productores e importadores, para que puedan establecer las medidas necesarias para gestionar los neumáticos luego de terminar su vida útil y darle su respectiva disposición final.

El Acuerdo Ministerial 098 (2015) hace mención a la Responsabilidad Extendida, en donde productores como importadores son responsables de los neumáticos usados durante todo el ciclo de vida, esto incluye todos los impactos que pudiera ocasionar desde su producción hasta su disposición final.

Para Brugues (2014) la Responsabilidad Social Empresarial (RSE) resulta necesaria como una herramienta que ayude a establecer un equilibrio entre los diversos actores que se involucran en esta temática, manifestándose como aquel aporte voluntario que realizan las empresas para conseguir el mejoramiento ambiental y socio-económico.

Dado que el dinamismo económico está en una evolución constante y a la par se muestran los problemas que conjuntamente trae este desarrollo, la responsabilidad social y ambiental es inevitable para poder conseguir la sostenibilidad. Esta investigación permitirá a los actores 
involucrados entender la importancia de la ética empresarial, sobre la base de esto los procesos de gestión de residuos tales como los neumáticos fuera de uso, podrían sufrir cambios profundos.

\section{METODOLOGÍA}

\section{Modalidad y tipo de investigación.}

La metodología a emplearse se basa en la recolección de datos secundarios fundamentado en la reciprocidad de las variables presentes en el tema investigativo, es decir, sobre responsabilidad social y disposición final de neumáticos usados. Rubio, Manjarrés y Rubio (2019) manifiestan que "todo fundamento circunstancial ha sido primordial en sus orígenes, y todo dato elemental, a partir del momento en que el investigador concluye su trabajo, se convierte en dato secundario para los restantes" (p.2).

Es una investigación de carácter exploratorio y descriptivo, dado que se realiza un diagnóstico actual con respecto la cantidad de neumáticos que se generaron en la ciudad de Machala durante el año 2019, mediante la recopilación de datos estadísticos obtenidos a partir de fuentes primarias, en este caso la Empresa de Movilidad de Machala. Acerca de la investigación exploratoria Lino, Meléndez, López y Soto (2018) manifiestan que "este tipo de indagación se centra en analizar e investigar aspectos concretos del entorno que aún no han sido analizados a fondo" (p.1).

También se emplea una investigación de tipo aplicada que para Siles (2018) "es la encargada de buscar aplicaciones a las teorías que den respuestas a los problemas de la sociedad" (p.3). Por ello se intenta proponer una solución a la problemática a través de la responsabilidad social y ambiental que permita a todos un tratamiento y disposición final a las llantas usadas de la ciudad de Machala.

El diseño de la investigación está compuesto por 3 fases metodológicas, las cuales se muestran en detalle en la Tabla 1.

\section{RESULTADOS}

La ciudad de Machala se encuentra localizada en la Provincia de El Oro (ver Figura 1). Presenta una extensión $207,09 \mathrm{~km}^{2}$ una población de 245.972 habitantes también se puede obtener una proyección para el año 2020 de 289.141 habitantes y para el 2030 de 315.982 habitantes, con una tasa de crecimiento anual del 1,36\%.

Según el INEC (2010) es posible establecer el número de hogares de un determinado sitio, ya que a nivel nacional la media de individuo por casa es de 3,78 para la ciudad de Machala para el año 2019, existen 75.963 hogares (Ver Figura 1).

Se ha podido identificar el estado actual de la problemática de las llantas usadas en la ciudad de Machala, esto mediante una visita a la Empresa Pública de Movilidad del Municipio de Machala, para saber la cantidad de neumáticos que se han generado en el año 2019 (ver Tabla 2).

Los neumáticos que mayormente generan residuos debido a su mayor uso son el rim 13 y 14 de los automóviles, y el rim 15 y 16 de las camionetas. Así también mediante estos datos podemos establecer una relación entre la población actual, el número de vehículos existentes y los neumáticos que se han generado. Como se puede apreciar, el número de vehículos está relacionado con el número de habitantes, siendo esta ciudad la de mayor densidad a nivel

Tabla 1.

Fases del diseño metodológico de la investigación

\begin{tabular}{ll}
\hline 1.- Fundamentación Científica & $\begin{array}{l}\text { 1.1 Análisis de fuentes de información primaria } \\
\text { 1.2 Análisis de fuentes de información secundaria (revisión artículos científicos, } \\
\text { estudios previos realizados a la temática planteada) }\end{array}$ \\
\hline \multirow{2}{*}{ 2.- Análisis Situacional } & $\begin{array}{l}\text { 2.1 Investigación campo } \\
\text { 2.2 Análisis de datos estadísticos }\end{array}$ \\
\hline \multirow{2}{*}{ 3.- Modelo de Gestión de Responsabilidad Social } & $\begin{array}{l}\text { 3.1 Características Modelo } \\
\text { 3.2 Plan de Modelo }\end{array}$ \\
\hline
\end{tabular}

Fuente. Tomado y adaptado de Propuesta de sistema de gestión de residuos sólidos urbanos para el municipio de Gamarra - Cesar, planteada desde la perspectiva de la responsabilidad social empresarial de Cortes Brugues, 2014, p. 50. 


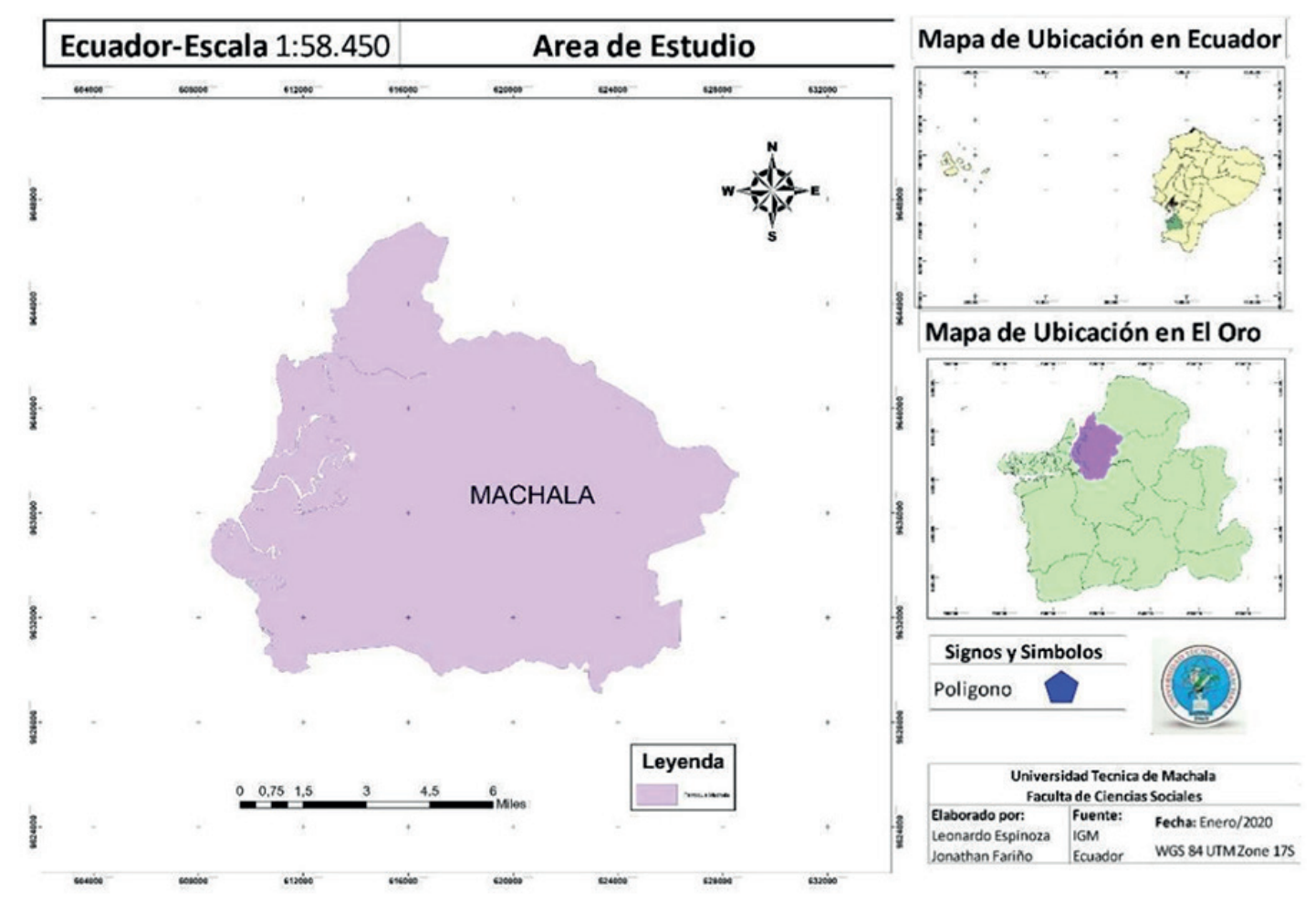

Figura 1. Mapa del área de estudio del Cantón Machala. Fuente: Instituto Geográfico Militar del Ecuador. Elaborado por los autores, 2020.

Tabla 2.

Neumáticos generados en el año 2019 en Machala

\begin{tabular}{|c|c|c|c|c|c|c|}
\hline Tipo de vehículo & $\begin{array}{l}\text { Número de } \\
\text { vehículos }\end{array}$ & $\begin{array}{l}\text { Número de } \\
\text { neumáticos }\end{array}$ & $\begin{array}{l}\text { Neumáticos } \\
\text { en uso }\end{array}$ & $\begin{array}{c}\text { Tiempo de cambio de } \\
\text { los neumáticos en el } \\
\text { año }\end{array}$ & $\begin{array}{c}\text { Neumáticos genera- } \\
\text { dos al año }\end{array}$ & $\begin{array}{l}\text { Número de rim } \\
\text { vehículos }\end{array}$ \\
\hline \multicolumn{7}{|c|}{ Vehículos Privados } \\
\hline Automóvil & 2863 & 4 & 11452 & 0,25 & 2863 & $13-14$ \\
\hline Camioneta & 2266 & 4 & 9064 & 0,3 & 2719,2 & $15-16$ \\
\hline Veh.utilitario & 2 & 4 & 8 & 0,25 & 2 & \\
\hline Veh. especial & 80 & 4 & 320 & 0,25 & 80 & \\
\hline Motocicleta & 4821 & 2 & 9642 & 0,2 & 1928,4 & $7-13$ \\
\hline Autobús & 7 & 6 & 42 & 2 & 84 & \\
\hline Camión & 400 & 6 & 2400 & 1,5 & 3600 & $16-22$ \\
\hline $\begin{array}{l}\text { Unidad de carga y } \\
\text { remolque }\end{array}$ & 23 & 6 & 138 & 1,5 & 207 & \\
\hline Subtotal & 10462 & & 33.066 & & 11484 & \\
\hline \multicolumn{7}{|c|}{ Vehículos Públicos } \\
\hline Automóvil & 139 & 4 & 556 & 0,25 & 139 & $13-14$ \\
\hline Camioneta & 65 & 4 & 260 & 0,3 & 78 & $15-16$ \\
\hline Veh. utilitario & 2 & 4 & 8 & 0,25 & 2 & \\
\hline Veh. especial & 49 & 4 & 196 & 0,25 & 49 & \\
\hline Motocicleta & 5 & 2 & 10 & 0,2 & 2 & $7-13$ \\
\hline Autobús & 433 & 6 & 2598 & 2 & 5196 & \\
\hline Camión & 157 & 6 & 942 & 1,5 & 1413 & $16-22$ \\
\hline $\begin{array}{l}\text { Unidad de carga y } \\
\text { remolque }\end{array}$ & 50 & 6 & 300 & 1,5 & 450 & \\
\hline subtotal & 900 & & 4870 & & 7329 & \\
\hline TOTAL & 11362 & & 37936 & & 18813 & \\
\hline
\end{tabular}

Fuente. Movilidad Machala EP. Elaborado por los autores, 2020. 
provincial y según lo previsto en cuanto al crecimiento poblacional, es muy probable también que el número de neumáticos aumente proporcionalmente.

En un estudio realizado por Ruiz (2019), menciona que en nuestro país a partir del 2018, se dispondrá de una cantidad cercana a 128.000 llantas usadas, que luego serán parte de residuos inservibles, lo cual se intensifica, teniendo en cuenta que el parque automotor va en constante aumento.

Según los datos proporcionados por Movilidad Machala existe para este año 2019 un total de 11.362 vehículos públicos y privados, por lo tanto, se produce una externalidad negativa hacia las personas esto debido a las fallas de mercado existentes, dado que se considera cuando el mercado no es eficiente para tratar los residuos que se genera y que la gente está dispuesta a pagar por ese bien o servicio. Fundación Vida Sostenible (2014), indica que una vez que estos neumáticos terminan su vida útil, muchos de ellos son abandonados en vertederos al aire libre, calles de las ciudades, terrenos baldíos, quebradas, ríos y esteros, que al no ser gestionados o tratados adecuadamente son medios propicios para la proliferación de mosquitos que provocan enfermedades al hombre tales como dengue y paludismo.

\section{Responsabilidad Social Empresarial.}

Después de realizado el diagnóstico acerca de los neumáticos fuera de uso que se originan en la ciudad de Machala, se toma en cuenta la metodología propuesta por la Organización Latinoamericana de Energía (OLADE, 2014), en un estudio realizado en el sector energético para la ejecución de acciones de la RSE, en donde manifiesta que la ISO 26000 es una herramienta que toma en cuenta la Responsabilidad Social Empresarial. El autor Avellán (2019) menciona que la RSE se ha constituido desde los años postreros una relevancia en las empresas y que por lo tanto constituye un paso importante para el logro de la misma dentro de las instituciones. Así mismo tenemos que los autores Lopéz, Ojeda y Rios (2017) definen a la RSE como un ejemplo de gestión donde las empresas públicas o privadas deben seguir para lograr el compromiso con el medio ambiente tomando en cuenta además la parte social y económica logrando generar el compromiso con la sociedad identificando los grupos de interés: comunidad, proveedores, autoridades, socios, capital humano, clientes, organismos y autoridades (ver Figura 2).

Modelo de gestión basado en la ISO 26000.

Para empezar, tenemos que la Responsabilidad Social se define como una guía de orientación,

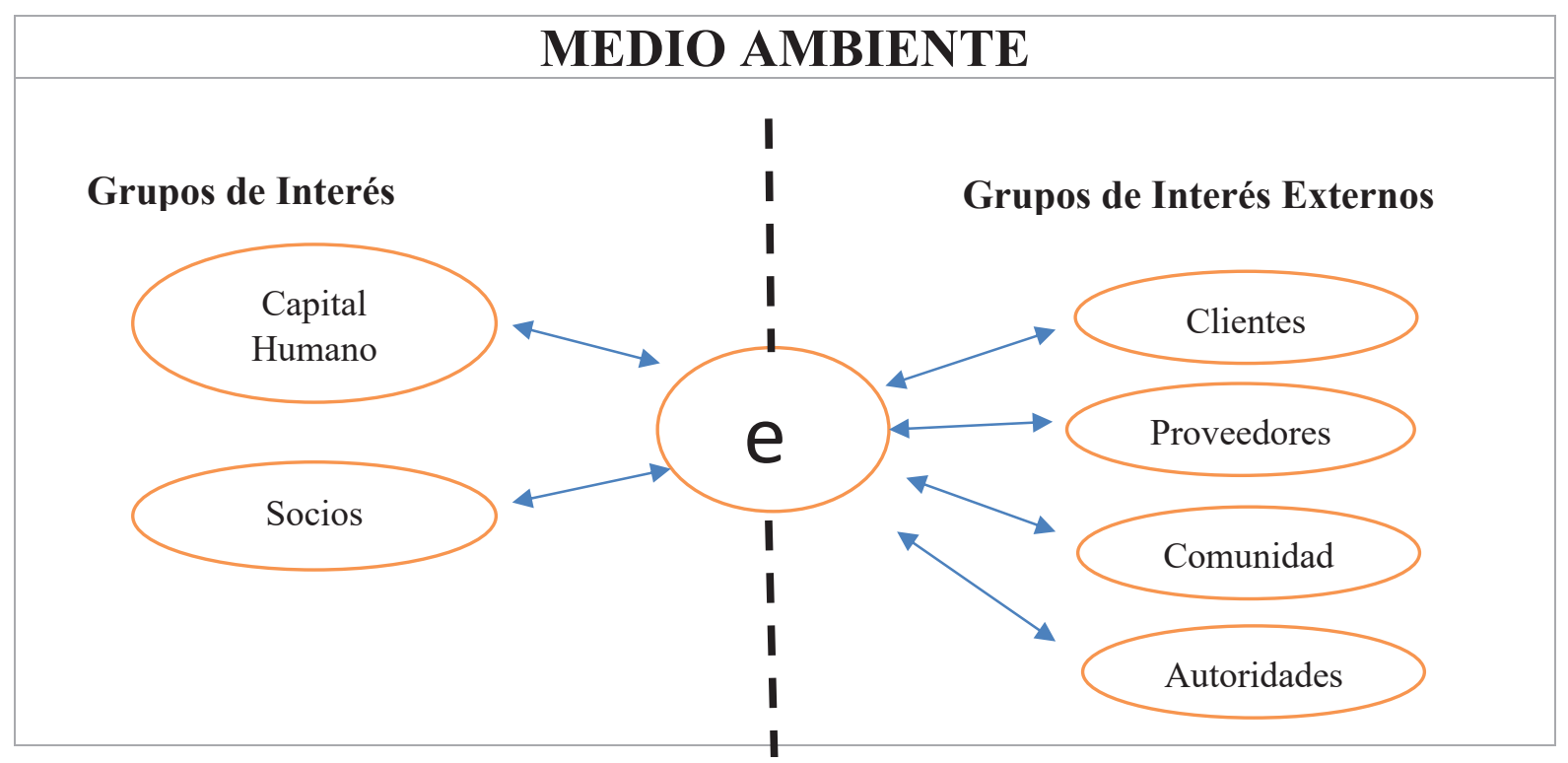

Figura 2. Identificación de los grupos de interés internos y externos. Fuente: Tomado de Andía, 2015. 
pertinente para todas las empresas en la cual se presenta un modelo de gestión que deben de seguir las empresas a nivel del mundo aplicando la responsabilidad social, directrices, principios dirigidos a los grupos de interés o también llamados los Stakeholder. (Lopéz, Ojeda, y Rios, 2017)

Para tal efecto se presenta los principios de la responsabilidad social en la Figura 3.

De igual manera esta norma recomienda que las empresas que opten por tener la Responsabilidad Social Empresarial necesitan tener ciertas características tales como se presenta en la Figura 4.

Según lo descrito, la Responsabilidad Social Empresarial, viene a ser un modo en el que tanto los empresarios de los neumáticos usados, entre los que se incluyen (importadores, distribuidores y comerciantes de neumáticos) junto con el sector público y la comunidad, puedan realizar un trabajo conjunto para que se pueda llegar a mejorar la problemática ambiental y la disposición final de los neumáticos usados.

\section{Definición estratégica del modelo de gestión de la Responsabilidad Social de la Planta de Asfalto perteneciente al Gobierno Autónomo Descentralizado Provincial (GADP) de El Oro.}

Para lo cual se define a continuación los lineamientos para la gestión de la RSE:

Misión: Actuar de manera responsable en la gestión ambiental de los neumáticos usados, coordinar acciones necesarias para la buena comunicación dentro de la organización de la institución.

Visión: Gestionar de manera sostenible los neumáticos usados para la determinación de un valor agregado por medio de la responsabilidad social a través de la coordinación de los representantes implicados en el proceso productivo.

Valores: Los valores que contará el Gobierno Autónomo Departamental de Potosí (GADP) de El Oro dentro de su estructura institucional son los siguientes:
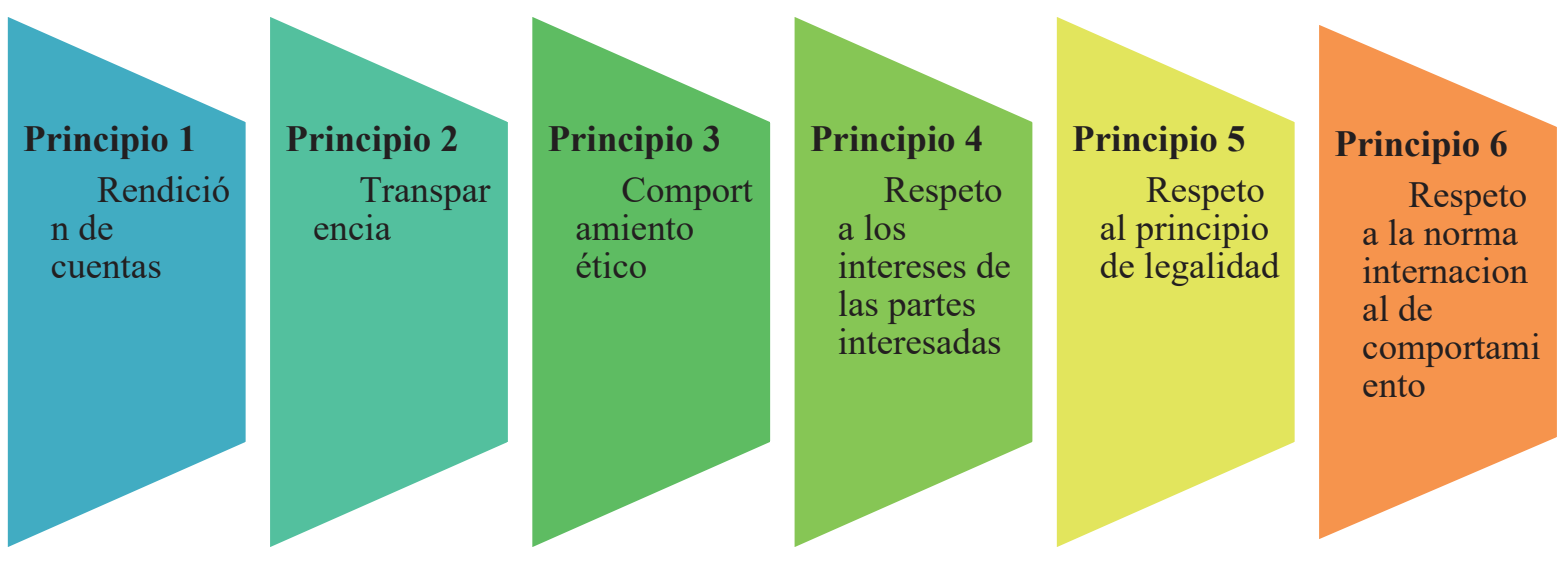

Figura 3. Principios de la Responsabilidad Social. Fuente: Norma ISO 26000:2010
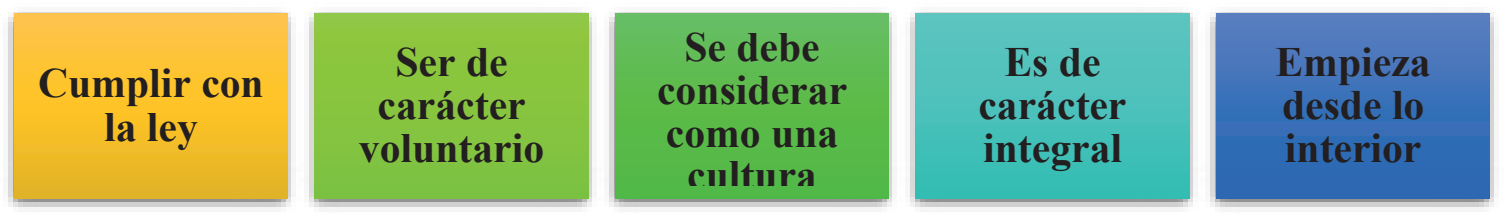

Figura 4. Características de la Responsabilidad Social para las empresas. Fuente: Organización Latinoamericana de Energía (OLADE), 2014. 
- Responsabilidad: Según Bauman (2007) menciona que la responsabilidad se constituye en una condición absoluta en relación a los seres humanos como los demás seres vivos, en los que se incluyen animales y plantas, que demandan la aplicación de normas que prevengan su deterioro (citado por Toca, 2017). Por lo tanto, el GADP de El Oro debe ser responsable con el ambiente, en cuanto a guardar las normas respectivas en cuanto al proceso de trituración de los neumáticos usados, para evitar posibles impactos tanto al entorno, como a las personas.

- Servicio de Calidad: El GADP de El Oro por medio de las políticas a implementarse en la responsabilidad social se compromete a proporcionar un servicio de calidad en lo que corresponde al proceso de los neumáticos hasta la obtención del producto final que es el caucho granulado.

- Trabajo en equipo: Este valor se ha vuelto esencial en la organización de una empresa, tal y como lo mencionan los autores Rojas, Jaimes y Valencia (2017) que para el éxito organizacional de una empresa la competitividad del trabajo en conjunto resulta primordial.

- Corresponsabilidad: En este caso, tanto la empresa como los empleados, cada parte demuestra su respectivo compromiso en pro de mejorar en su funcionamiento, comunicación y rendimiento, los empleados que formen parte de la planta de trituración tendrán una especial atención en sus labores, incluyendo a los funcionarios que se encuentren al mando de dicha actividad.

- Liderazgo: De igual manera, el liderazgo en las instituciones es fundamental debido a que contagia de un espíritu de servicio y de mejoramiento continuo, el líder se convierte en un modelo a seguir, además de que ordena las acciones encaminadas a la consecución de los éxitos, Bass (1999), citado de Enderica, Almeida, Chamba \& Tinoco (2018) agrega que "estas muestras logran incrementar la producción, satisfacción y desarrollo de un liderazgo convincente, demostrando su originalidad e importancia".

\section{Objetivos estratégicos.}

- Gestionar de manera adecuada los recursos que cuenta la planta para un mejor integrado del procesamiento de los neumáticos fuera de uso.

- Coordinar acciones necesarias para la implementación de medidas que vayan apegado con el desarrollo sostenible y el buen manejo de los desechos sólidos.

- Impulsar un modelo de responsabilidad social dentro de la institución para articular acciones que vayan en el aprovechamiento de la materia prima del caucho para su procesamiento

- Promover la cadena de valor a través de la generación de un valor agregado tomando en cuenta la competitividad y además de la implementación de una cadena de valor.

- Establecer políticas institucionales que vayan encaminadas a las prácticas operacionales de la responsabilidad social.

- Desarrollar una comunicación con todo el personal administrativo con la finalidad de dirigir acciones coordinadas con la empresa y mejorar su competitividad institucional en materia ambiental.

\section{La organización del modelo de gestión de la Responsabilidad Social.}

Para poder ubicar de manera correcta en el organigrama la función de la Responsabilidad Social del GADP de El Oro.

A continuación, se propone el siguiente modelo de gestión de responsabilidad social para la Planta de Trituración de Neumáticos Usados, la misma que se fundamenta en la importancia de poder incluir en su estructura organizativa la unidad de Apoyo en la cual funcionará el área de Responsabilidad Social encaminada a la gestión integral de los neumáticos en desuso para el aprovechamiento del caucho granulado para obtención de un producto elaborado.

Por medio de la presente propuesta del modelo de gestión se pretende lograr crear actitudes y comportamientos de acción inmediata ante una respuesta a la parte ambiental logrando ser una institución socialmente responsable 
estableciendo responsabilidades en el entorno social y sobre todo tomando como principales protagonistas a los miembros que conforman cada uno de los departamentos como también a los diferentes actores involucrados tales como (importadoras de llantas y la sociedad en general) la misma que sus acciones directas ejercen un impacto ante la problemática de las llantas en desuso y de cómo poder llegar a gestionarla adecuadamente, además de fortalecer la imagen de la institución ante estas situaciones.

Para aplicar acciones inmediatas para la responsabilidad social identificados en la planta de asfalto se debe de enfocar de establecer lazos de cooperación en el cual se pueda trabajar en conjunto con instituciones que lleven a cabo el manejo de las llantas, para ello se ha determinado que para poder aplicar el modelo de responsabilidad social se debe de comenzar con la creación de políticas que vayan encaminadas a la responsabilidad de la institución.

El GADP de El Oro a través del Departamento de la Secretaría de Gestión Ambiental que tiene bajo cargo la parte ambiental, se propone la presente política que vaya encaminada al buen funcionamiento de la planta de asfalto que está bajo a cargo de la misma ante mencionada y que es necesario que para lograr un buen desempeño y cumplir con la parte ambiental se concluye que es necesario que se comenzara a crear políticas que ayuden a fortalecer lazos de cooperación, participación, alianzas con todos los actores involucrados en la venta y comercialización de los neumáticos usados.

A continuación, se detalla las políticas que ayudará al buen manejo de la planta de asfalto "El Pedregal":

\section{Propuesta de política para el desempeño ambiental de la planta de asfalto por parte del GADP de El Oro como un medio para lo- grar la responsabilidad social y ambiental.}

- Redactar memoria de Sostenibilidad de manera anual y bianual tomando en cuenta las directrices presentadas por parte del Global Reporting Initiative (GRI).

- Presentar a tanto a los nuevos como a los históricos proveedores con los que cuenta la planta de asfalto.
- Coordinar las tareas para ejecución del sistema de diálogo con los grupos de interés identificados (gestores, comerciantes, puntos de ventas de llantas, consumidores y autoridades).

- Reducir los impactos ambientales negativos que se generan dentro de la planta de asfalto debido a las actividades que se realizan para el procesamiento de reciclaje y trituración de los neumáticos.

- Contar con un Plan de Emergencia ante situaciones de que se tenga que actuar de manera rápida frente a un problema ambiental.

\section{DISCUSIÓN}

En base a este tipo de investigación se relaciona este enfoque con el estudio propuesto por el autor Brugues (2014) para el manejo integral de los desechos en Bucaramanga, donde se menciona un modelo de responsabilidad empresarial basado en la norma ISO 26000, a partir de este modelo se plantea adaptarlo a nuestra realidad local, en este caso para la gestión de los neumáticos usados en la ciudad de Machala. Además se puede contrastar que ambas directrices presentados se puede mencionar en un estudio realizado por Brugues en comparación con la guía propuesta por Tapia (2017), sobre un modelo de responsabilidad social aplicado para una institución educativa por lo tanto se indica que este modelo logra la responsabilidad social dentro de la estructura organizacional por lo que se propone que se crea una unidad de apoyo en el cual pueda complementarse con los demás departamentos del GAD Provincial la misma que estaría operando dentro de la instalaciones de la planta de trituración de los neumáticos para poder llevar el control y manejo de la operación de la llanta.

\section{CONCLUSIONES}

Realizando el diagnóstico situacional, se puede afirmar Cantón Machala es el centro productivo y económico de la provincia de El Oro; sin embargo, debido a este rápido crecimiento económico se ha podido constatar que el parque automotor de igual manera ha ido creciendo generando importantes eventos que producen impactos tanto en el ambiente como en la sociedad, este es el caso de los Neumáticos Fuera de 


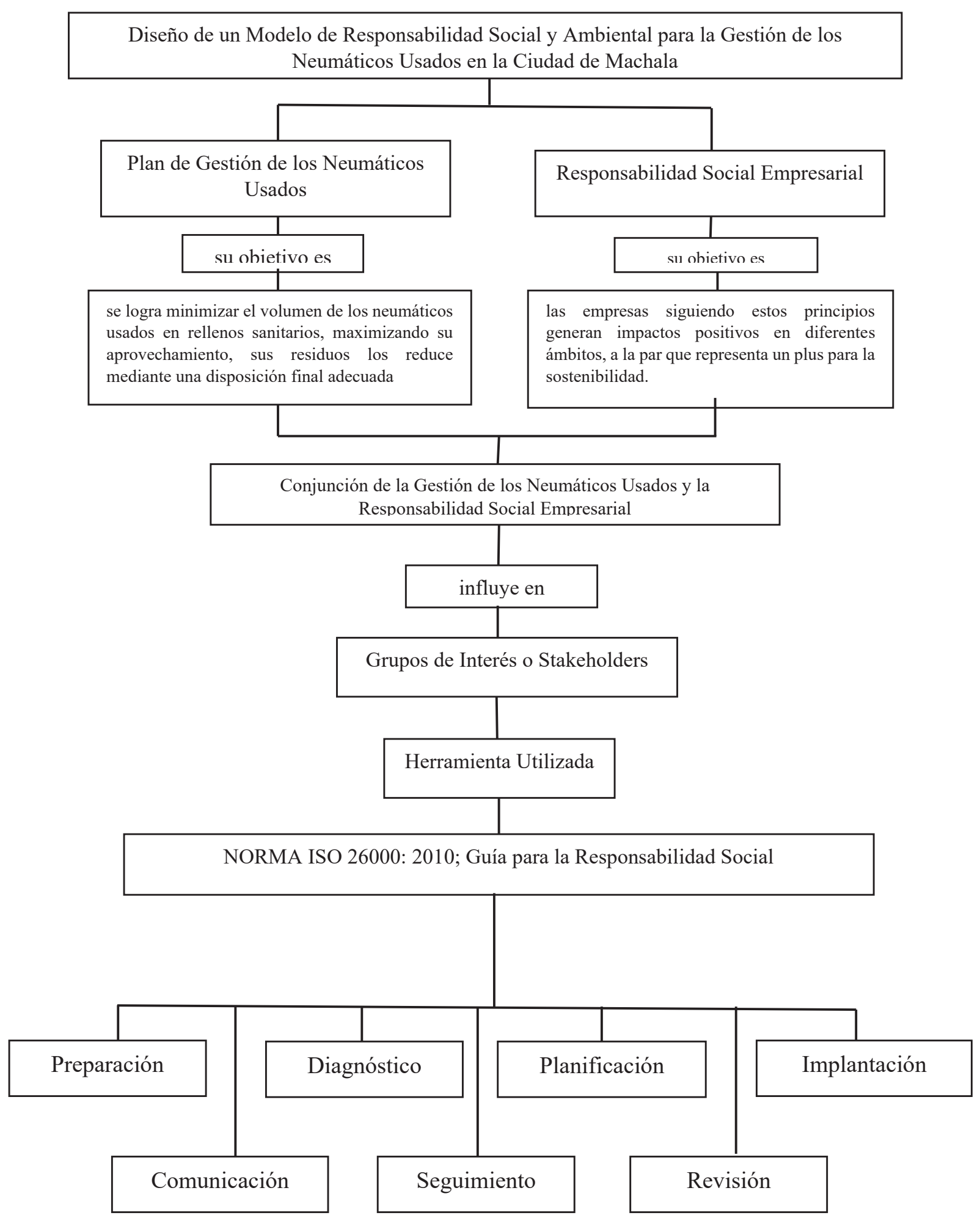

Figura 5. Esquema para la implementación de responsabilidad social en la planta de trituración de neumáticos, perteneciente al GADP de El Oro.

Fuente: Tomado y adaptado de Cortes Brugues, 
Uso, que necesitan ser gestionados de una mejor manera para tener una correcta disposición final. Como parte de la investigación bibliográfica realizada, se propone un modelo de gestión basado en las Norma ISO 26000, la cual habla de la Responsabilidad Social Empresarial, la misma que promueve una política en la que toma en cuenta a los colectivos significantes que se aprecian claramente y de alguna manera afectados por este tipo de residuos, para ello esta norma suscita una forma de actuar fundamentado en la ética empresarial, los mismos que permiten un equilibrio en las dimensiones económico, social y ambiental para poder conseguir el desarrollo sostenible.

\section{REFERENCIAS BIBLIOGRÁFICAS}

Andía, W. (2015). La Responsabilidad Social: Análisis del Enfoque de ISO 26000. Revista de la Facultad de Ingeniería Industrial, 1-5.

Avellán, N. (2019). Contabilidad Ambiental y la Responsabilidad Social Empresarial dentro del panorama mundial del desarrollo sostenible. Revista ECA Sinergia, 105-115.

Castro, A., Meléndez, L., López, G. y Soto, I. (2018). La investigación exploratoria aplicada como estrategia didáctica en el laboratorio. Revista Electrónica sobre Cuerpos Académicos y Grupos de Investigación, 1 - 9.

Cortes, I. (2014). Propuesta de sistema de gestión de residuos sólidos urbanos para el municipio de Gamarra - Cesar, planteada desde la perspectiva de la responsabilidad social empresarial. Maestría para el urbanismo y el desarrollo territorial sostenible. Universidad de Santander - Facultad de Derecho, Bucaramanga.

Enderica, O., Almeida, K., Chamba, S. y Tinoco, E. (2018). Implementación de un liderazgo empresarial que mejore la comunicación efectiva en las empresas de una ciudad ecuatoriana. Ciencia UNEMI, 96 - 105.

ETRma. (2011). European Tyre \& Rubber Industry. Obtenido de Statistics. Edition 2011. no3.

Fundación Vida Sostenible; (2014). Revolución en reciclaje de neumáticos. Obtenido de vidasostenible.org: http://www.vidasostenible.org/ revolucion-en-reciclaje-de-neumaticos/

Lopéz, A., Ojeda, J. y Rios, M. (2017). La responsabilidad social empresarial desde la percepción del capital humano. Estudio de un caso. Revista de Contabilidad, 15. DOI: https://doi.org/10.1016/j.rcsar.2016.01.001
Ministerio del Ambiente y Agua (2013). La Gestión Integral de Neumáticos Usados optimiza recursos para el manejo seguro de desechos. Obtenido de http://www.ambiente.gob.ec/la-gestion-integral-de-neumaticos-usados-optimiza-recursos-para-el-manejo-seguro-de-desechos/

Ministerio del Ambiente y Agua (2015). Acuerdo Ministerial 098. Instructivo para la Gestión de Neumáticos Usados. Ecuador.

Norma ISO 26000. (2010). Norma Internacional, Guia de Responsabilidad social. Ginebra.

Organización Latinoamericana de Energía (OLADE). (2014). Metodología para la implementación de acciones de RSE en empresas del sector energético con equidad de género.

Rojas, M., Jaimes, L. y Valencia, M. (2017). Efectividad, eficacia y eficiencia en equipos de trabajo. Espacios, 11.

Rubio, S., Martín, S. y Rubio, S. (2019). Aspectos metodológicos de la instrumentalización de la recogida de datos primarios y sus consideraciones éticas en la investigación clínica. Enfermería en cardiología: revista científica e informativa de la Asociación Española de Enfermería en Cardiología, (76), 21 - 26.

Ruiz, J. (2019). Neumáticos de larga duración en buses de transporte para reducción de emisiones de carbono. Espacios, 19.

Siles, J. (2018). La humanización del cuidado a través de las narrativas y la poesía como producto de la investigación aplicada. Cultura de los cuidados (Edición digital), 9 - 15.

Tapia, L. (2017). Responsabilidad Social Universitaria.Una propuesta de modelo de gestión socialmente responsable para la Universidad Técnica Particular de Loja. Trabajo de titulación. Universidad Técnica Particular de Loja, Loja.

Toca, C. (2017). Aportes a la responsabilidad social. Revista Mexicana de Ciencias Políticas y Sociales, 393 - 407. doi:https://doi.org/10.1016/S01851918(17)30033-8

Velva, H. (2017). Planta de tratamiento de neumáticos fuera de uso. Trabajo de titulación en la modalidad de emprendimiento previo a la obtención del título de Ingeniero de Organización de empresas. Universidad Técnica de Ambato, Ambato. 